\title{
Isolation and characterization of cDNA clones encoding a novel subfamily sporamin B in sweet potato
}

\author{
JOLLANDA EFFENDY ${ }^{1, \boldsymbol{v}}$, DON R. LABONTE ${ }^{2}$, DARDA EFENDI ${ }^{3}$ \\ ${ }^{1}$ Department of Plant Breeding, Faculty of Agriculture, Universitas Pattimura. Jl. Ir. M. Putuhena, Poka Campus, Ambon 97233, Maluku, Indonesia. \\ Tel.: +62-911-322499, `email: jeffendy@alumni.sfu.ca \\ ${ }^{2}$ School of Plant, Environmental, and Soil Sciences, Louisiana State University Agricultural Center. 131 J.C. Miller Hall, Baton Rouge, LA 70803, USA \\ ${ }^{3}$ Department of Agronomy and Horticulture, Faculty of Agriculture, Institut Pertanian Bogor. Jl. Meranti, IPB University Campus Dramaga, Bogor \\ 16680, West Java, Indonesia
}

Manuscript received: 12 August 2019. Revision accepted: 25 September 2019.

\begin{abstract}
Effendy J, Labonte DR, Efendi D. 2019. Isolation and characterization of cDNA clones encoding a novel subfamily sporamin B in sweet potato. Biodiversitas 20: 3033-3041. Three cDNAs ( $\mathrm{IbH} 23, \mathrm{IbH} 41$, and $\mathrm{IbH} 74)$ encoding sporamin of sweet potato, were isolated from a skinning injury cDNA library. The open reading frame consisted of 288 nucleotides and the deduced polypeptide sequences consist of 96 amino acids with missing 127 amino acid residues at 5'. The sequences shared identity [42-62\% (IbH23 and $\mathrm{IbH} 41$ ) and 40-61\% ( $\mathrm{IbH74})]$ to sporamins A and B previously identified in other sweet potato species. The IbSpors contained three of four signature cysteine residues of sporamin family (Cys135, Cys198, Cys209). In addition to similarity to sporamins, these cDNA clones also showed similarities to miraculin (29-35\%); Kunitz trypsin inhibitor (29-36\%); factor Xa inhibitor (32-38\%); subtilisin inhibitor (26-37\%); seed protein (32\%); tumor-related protein (36\% in $\mathrm{IbH} 23$ and $\mathrm{IbH} 41)$; and [wound-responsive protein (30\%), sexual organ responsive protein $(29 \%)$, and proteinase inhibitor $(26 \%)$ can only be found in $\mathrm{IbH} 74]$. The three partial mRNA transcripts showed induced and transient expression in response to skinning injury. The phylogenetic analysis revealed that they belonged to a new member of sporamin gene subfamily B and may play key roles in plant defense and wound repair in response to skinning injury in storage roots of sweet potato.
\end{abstract}

Keywords: Cysteine residues, Ipomoea batatas, miraculin, storage root, wounding

\section{INTRODUCTION}

Sweetpotato is the second most important storage crop after cassava (FAO 2016). World sweet potato production is estimated at $130 \mathrm{Mt}$ (FAO 2016). It is the main staple food in 82 countries, in which almost all of them are developing countries (FAO 2016). Indonesia is the world's fifth-largest sweet potato producer in the world with total production of $2.270 \mathrm{Mt}$ and total harvested area of 0.137 MHa with an average yield of 16.6 ton/ha (FAO 2016). The high starch content in sweet potato fulfills calorie needs in many countries. As valuable starch reserves, however, post-harvest loss was huge due to wound injury especially in underprivileged countries (Booth and Burton 1983; Rees et al. 2003).

Storage substances such as starch, lipids, and proteins are accumulated at different stages of plant development (Fujiwara 2002). They can be found in vegetative and reproductive tissues and function as reserves for further use (Fujiwara 2002). Storage proteins function as biological reservoirs for nitrogen, sulfur, and carbon (Shewry 2003). They are usually found in seed and tuberous roots of plants species to provide nutrients to support the growth of new plants (Shewry 2003). Vegetative and reproductive tissues highly accumulate proteins in protein bodies, so that they do not interfere with other cellular functions (Shewry 2003). Examples include patatin in potato tuber (Dutt et al. 2014), dioscorins in yam (Xue et al. 2015), glutelin in wheat (Scherf et al. 2016), ocatin in Andean tuber crop oca (Flores et al. 2002) and sporamin in sweet potato (Effendy et al. 2013; Effendy et al. 2017; Ponniah et al. 2017).

Sporamin, a vacuolar storage protein, is exclusively found in storage roots of sweet potato (Hattori et al. 1989). It is a major storage protein and represents $60-80 \%$ of the total soluble protein of sweet potato storage roots (Maeshima et al. 1985). It shares significant amino acid sequence identity with some Kunitz-type trypsin inhibitors (Hattori et al. 1991). There are two classes of sporamins, sporamin A (spor A) and sporamin B (spor B) (Hattori et al. 1985). Based on electrophoresis analysis and the intensity of bands, Maeshima et al. (1985) found that the ratio of spor A to spor B content was 2:1. They showed that the molecular weight of Spor A was 31000 Da and spor B was 22000 Da (Maeshima et al. 1985).

Previous studies showed that sporamin belongs to a multigene family (Hattori et al. 1989). Various sporamin genes have been isolated from many Ipomoea species (Altschul et al. 2005). BLASTX search showed that Spor A genes have been isolated from Ipomoea batatas, I. trifida, I. leucantha, and I. nil, while spor B genes have been isolated from I. batatas and I. nil only (Altschul et al. 2005).

Sporamin has attracted the attention of an increasing number of researchers due to its role against pests and herbivores in the vegetative tissues of plants (Yeh et al. 1997; Ding et al. 1998; Rajendran et al. 2014). The fact that 
sporamin levels are highly regulated in response to a wide range of biotic and abiotic stress responses showed the importance of this gene in stress-related responses (Senthilkumar and Yeh 2012; Effendy et al. 2013; Qiu et al. 2013; Rajendran et al. 2014; Effendy et al. 2017).

Here, we report the isolation and characterization of sweet potato partial cDNA clones encoding sporamin which is a new subfamily of spor B. This sporamin may play key roles in plant defense and wound repair in response to skinning injury in storage roots of sweet potato. The cDNAs sequences, similarity, and phylogenetic analysis among related genes are discussed in this paper.

\section{MATERIALS AND METHODS}

\section{Plant materials}

Freshly harvested storage roots of sweet potato cultivar LA 07-146 were washed, blot-dried, and carefully scraped with a razor scraper (Titan 11030; Star Asia-USA, Renton, WA) to remove the thin outer pigmented skin as detailed in Effendy et al. (2013). The roots were skinned and the skinned roots were peeled to the same thickness $(1.2 \mathrm{~mm})$ at 0 (control), 2, 4, 8, and $12 \mathrm{~h}$ after skinning and the peels were immediately frozen in liquid nitrogen and stored at $80{ }^{\circ} \mathrm{C}$ for RNA extraction. Three independent roots were used for each time points as replicates.

\section{RNA isolation, cDNA preparation. and ACP-based gene-fishing PCR}

Total RNA was extracted using the RNeasy Mini Kit (Qiagen, Valencia, CA) as outlined in manufacturer's instructions (Effendy et al. 2013; 2017). The quantity and quality of the total RNA were determined using a spectrophotometer (ND-1000; Nanodrop Technologies, Wilmington, DE). An aliquot of $2 \mu \mathrm{g}$ RNA of three biological replicates extracted from storage root tissues for each time point was pooled to capture rare transcripts that may have escaped in one of the replicates as a result of technical errors during gene fishing experiment. Also, $3 \mu \mathrm{g}$ RNA extracted from storage roots at 8 and $12 \mathrm{~h}$ were pooled together to make the sample size of four for convenience with PCR handling during gene fishing.

First-strand cDNA synthesis was performed using a Gene- Fishing ${ }^{\mathrm{TM}}$ DEG premix kit (Seegene, Rockville, MD) as previously described (Effendy et al. 2013). Second strand cDNA synthesis and subsequent PCR amplification were performed in a single tube as previously described (Effendy et al. 2013). Twenty ACP primers were used during the second-stage PCR and subsequent PCR amplification were performed in a single tube using the protocol as detailed in the GeneFishing ${ }^{\mathrm{TM}}$ DEG premix kit manual (Seegene, Rockville, MD) in present study to capture the DEGs.

\section{Cloning of Differentially Expressed Genes (DEGs)}

Based on presence/absence or relative intensity of ACPPCR products between control and skinning samples, the fragments corresponding to DEGs were excised and extracted following the manufacturer's instruction
(QIAquick® Gel Extraction Kit Qiagen, Valencia, CA). The DEGs were cut from the gel and cloned into pGEM®$\mathrm{T}$ Easy vector (Promega, Madison, WI). The positive colonies from DEGs were confirmed by colony PCR using M13F and M13R primers. Plasmids isolated from these clones were single-pass sequenced with $\mathrm{T} 7$ primer in an ABI $3730 \times 1$ genetic analyzer according to the manufacturer's instruction.

\section{Nucleotide and deduced amino acid sequencing analyses of $D E G s$}

DNA sequences were processed manually to remove the vector backbone and the poly (A) tail and searched against the nonredundant nucleotide and protein database of NCBI using BLASTN and BLASTX interface (http://www.ncbi.nlm.nih.gov/BLAST). Three positive cDNAs clones showed similarity to a storage protein sporamin were named $\mathrm{IbH} 23, \mathrm{IbH} 41$, and $\mathrm{IbH} 74$ were used for further analysis. A total of 100 hits from BLASTX search that showed similarities to $\mathrm{IbH} 23,-41$, and -74 were pooled based on the type of genes and the number of occurrence of each gene, and for Ipomoea sp. also based on the type of sporamins. Alignment and comparison of sequences were made using the ClustalW program (http://www.ebi.ac.uk/clustalw) to find the homologs and to predict the functions of the differentially expressed genes/gene products to generate multiple sequence alignment in which three samples were chosen to represent each gene.

Open reading frame and protein prediction were made using the NCBI ORF (http://www.ncbi.nlm.nih.gov/gorf/gorf.html). Conserved amino acid sequences were indicated by BOXSHADE 3.21 [http://www.ch.embnet.org/software/BOX_form.html]. The unrooted phylogenetic tree was generated from the deduced amino acid sequences for IbSpor cDNA clones and other Spors homologs from other Ipomoea species and other genes from other plants that showed similarities by using the bootstrap method with 1,000 bootstrap iterations. This tree represents the branching order but does not indicate the root or location of the last common ancestor. To construct the phylogenetic tree, the .dnd file generated in ClustalX2 was displayed in FigTree v1.4.3.

\section{RESULTS AND DISCUSSION}

\section{Isolation and analysis of candidate partial cDNAs using ACP GeneFishing}

To examine the effect of skinning injury on storage root RNA population and to determine how rapidly the changes in mRNA population occurred following the onset of a skinning injury, time-course experiments were carried out. RNA was isolated from freshly harvest storage roots exposed to skinning injury at $0,2,4$, and combined $(8+$ 12) $\mathrm{h}$ and used for ACP-PCR. IbH23 and $\mathrm{IbH} 74$ showed higher expression at $8+12 \mathrm{~h}$, while IbH41 showed a high expression level at $2 \mathrm{~h}$ following the onset of skinning injury treatment (Figure 1 and Table 1). Under non-stress conditions, sporamin is constitutively expressed in storage 
root of sweet potato (Wang et al. 2002). In this study, ACPPCR products of $\mathrm{IbH} 23,-41$, and -74 have different peaks in response to skinning injury. These results showed that upon the onset of skinning injury, sporamin mRNA transcripts were transiently and up-regulated. Rapid induction of spor at $2 \mathrm{~h}$ in IbH41 might indicate its defense role in wound healing. This study and others showed that spor was differentially expressed in leaves and roots in response to wounding (Yeh et al. 1997; Effendy et al. 2013; Effendy et al. 2017), abiotic (Senthilkumar and Yeh 2012) and biotic (Qiu et al. 2013) stresses, suggesting that spor may be a stress-responsive gene. These expression patterns at the transcriptional levels revealed that the complex regulatory mechanism of sporamin was modulated by environmental cues. Therefore, these cDNAs could be considered as key target genes to be used in genetic engineering to study molecular evolution, regulatory mechanisms and physiological functions in plants.

\section{Isolation of three cDNAs encoding sporamin from storage roots of sweet potato}

Three ACP primers used in the experiment demonstrated changes in the amplification of DEGs in storage roots after skinning injury at $0,2,4,(8+12) \mathrm{h}$. Three cDNA clones were isolated and their sequences were determined. The cDNA products of interest were excised, re-amplified and then cloned. The insert of each cDNA clone was sequenced. Each of the cDNA sequences was submitted to the NCBI server for comparison to sequences available in the GenBank nucleotide and expressed sequence tag (EST) databases using BLAST programs. The $\mathrm{IbH} 23,-41$, and -74 cDNAs contained $388 \mathrm{bp}, 414 \mathrm{bp}$, and $414 \mathrm{bp}$ of nucleotides, respectively, each containing an open reading frame of $288 \mathrm{bp}$ (Figure 2). Thus, the $\mathrm{IbH} 23$, -41 , and -74 cDNAs covered partial length of the sporamin mRNA sequences. Based on their percent identity, these three clones shared high identity among themselves. IbH23 and $\mathrm{IbH} 41$ shared 99\% identity; $\mathrm{IbH} 23$ and $\mathrm{IbH} 74$ shared 92\% identity; and $\mathrm{IbH} 41$ and $\mathrm{IbH} 74$ shared 94\% identity (Figure 2).
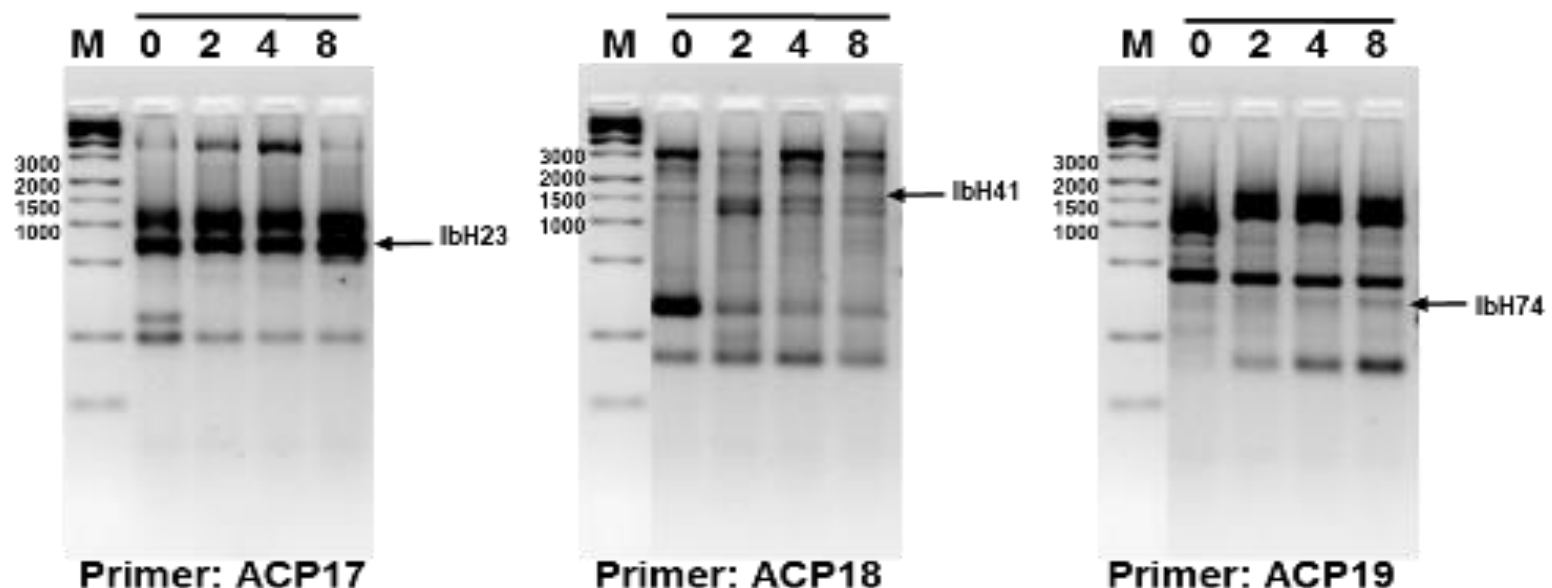

Figure 1. ACP-PCR products of mRNA isolated from non-treated $(0 \mathrm{~h})$, and skinning injury treatment for 2,4 , and $(8+12) \mathrm{h}$ of sweet potato storage roots. ACP-PCR was performed with primers ACP17, ACP18, and ACP19. Arrows marked indicate ACP-PCR products that were excised from the gel and cloned. Differential display of sweet potato cDNA GeneFishing showed amplification products of $\mathrm{IbH} 23$, IbH41, and $\mathrm{IbH} 74$ using ACP arbitrary primers ACP17, ACP18, and ACP19, respectively at 0, 2, 4, and (8 + 12) h after skinning treatments. ACP: annealing control primer; M: DNA ladder marker. Arrows indicate differential amplified cDNA bands.

Table 1. Accumulation of ACP-PCR products corresponding to RNA in response to skinning injury treatment in sweet potato

\begin{tabular}{llcccc}
\hline cDNA & Type & $\mathbf{0 ~ h}$ & $\mathbf{2}$ h & $\mathbf{4 h}$ & $\mathbf{( 8 + 1 2 ) \mathbf { h }}$ \\
\hline IbH23 & Skinned up-regulated & + & + & + & ++ \\
IbH41 & Skinned transient regulated & + & +++ & ++ & + \\
IbH74 & Skinned up-regulated & + & + & + & ++ \\
\hline
\end{tabular}

Type up-regulated and transient regulated correspond to groups of ACP-PCR products with different accumulation patterns. '+", '+十' and ' +++ ' denotes the presence and relative intensity of ACP-PCR products on agarose gels. 


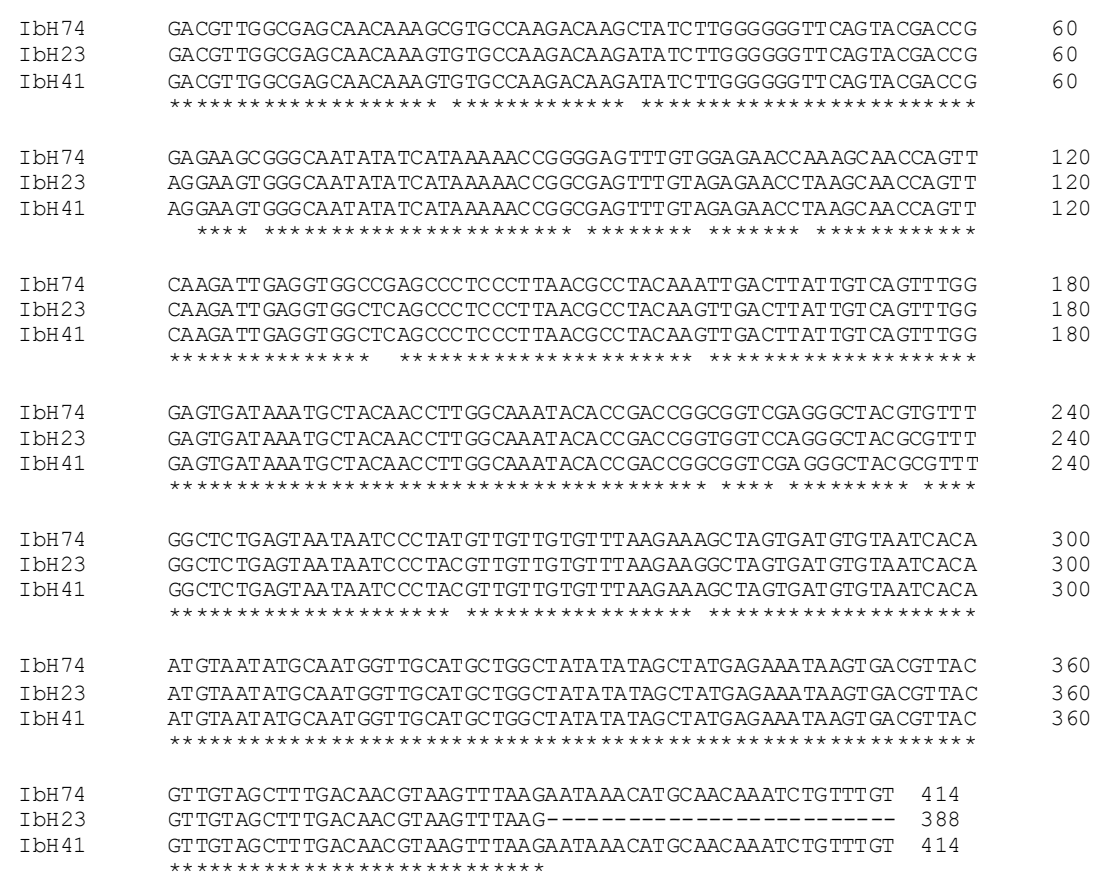

Figure 2. Sequence alignment of three partial cDNA clones $\mathrm{IbH} 23$, IbH41, and $\mathrm{IbH} 74$ in response to skinning injury in sweet potato. Star (*) represented same nucleotides, empty space ( ) represented 1/3 nucleotide differences and dash (-) represented deletions

\begin{tabular}{|c|c|}
\hline pIM0336 & taaTGA GCACC------GGTGTTGAGGT TGCATGCATGTTA--TGGAGCTA TGCTA \\
\hline $\mathrm{IbH} 74$ & ---taaTCACAATGTAATATGCAATGGTTGCATGCTGGCTATATATAGCTATGAGA $\overline{\overline{\text { ATA }}}$ \\
\hline IbH 23 & ---taaTCACAATGTAATATGCAATGGTTGCATGCTGGCTATATATAGCTATGAGA $\overline{\mathbf{A A T A}}$ \\
\hline $\mathrm{IbH} 41$ & $\begin{array}{l}-- \text { taa TCACAATGTAATATGCAATGGTTGCATGCTGGCTATATATAGCTATGAGA } \\
\text { AATA }\end{array}$ \\
\hline pIM0336 & AGT-----AACGT TGCAACTT TGACAACGTTGTACG TG TAA TAATAAG AAAAACA TGCA \\
\hline $\mathrm{IbH} 74$ & AGTGACGTTACGT TGTAGCTT TGACAACGTAA------- GT TTAAG AATAAACA TGCA \\
\hline I bH 23 & 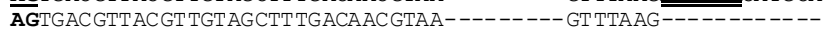 \\
\hline $\mathrm{IbH} 41$ & AGTGACGTTAC GT TGTAGCTT TGACAACGTAA-------- GT TTAAG AATAAACA TGCA \\
\hline & 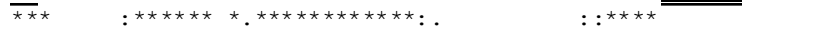 \\
\hline pIM0336 & СTAAATCCGAGCTTGTTGTGTTGTGTAAATTTTAACTATCTTTAAATGAATAAGCATAAT \\
\hline $\mathrm{IbH} 74$ & ACAAAT C TGTTTGT-- \\
\hline $\mathrm{IbH} 23$ & - \\
\hline $\mathrm{I}$ bH 41 & ACAAATCTGTTTGT---- \\
\hline
\end{tabular}

Figure 3. Sequence analysis of $3^{\prime}$-untranslated region among three partial cDNA clones of sweet potato in response to skinning injury and pIMO336 from sweet potato. All sweet potato clones showed putative eukaryotic polyadenylation signal in 3 '-UTR sequence. The consensus polyadenylation recognition sequences AATAAA and AATAAG were sìngly and double underlined, respectively

Analysis of the $3^{\prime}$ untranslated region (UTR) region of the three cDNA clones and a sporamin B subfamily pIMO336 (Hattori et al. 1990) definitely showed a low (27/96) and medium (54/100) identity among these clones without and with the exception of the deletions and substitutions of several bases, respectively (Figure 3). The 3' UTR of IbH23, -41, and -74 with pIMO336 encoding spor B from sweet potato showed a shifting stop codon (taa) in IbH23, -41, and -74 when compared with pIMO336 (Murakami et al. 1986).

The sequence alignment showed that polyadenylation recognition consensus sequences (AATAAG) occurred at 37 for $\mathrm{IbH} 23$; 20 for $\mathrm{IbH} 41$ and $\mathrm{IbH} 74$; while sequences (AATAAA) occurred at 63 for $\mathrm{IbH} 41$ and $\mathrm{IbH} 74$ nucleotides upstream of the poly (A) site of sporamin genes. No AATAAA sequence was found in $\mathrm{IbH} 23$ (Figure 3) (Dean et al. 1986). Also, a G/T cluster (tri-nucleotide TGT), TGTTTGT (similar to mammalian cells signal of YGTGTTYY) was found downstream of AATAA sequence and before poly (A) site of $\mathrm{IbH} 41$ and $\mathrm{IbH} 74$ cDNA clones (Figure 3 ). The G/T cluster was proposed to have function in the RNA processing events (Dean et al. 1986). Analysis of the 3'-UTR sequence of the three cDNA clones showed a notable difference between $\mathrm{IbH} 23,-41$, and -74 with spors $A$ and B. G/T cluster commonly found in spors $\mathrm{A}$ and $\mathrm{B}$ was not found in all these cDNAs. Instead, the three cDNAs showed short palindromic sequences TGTTGT (Figure 3). 


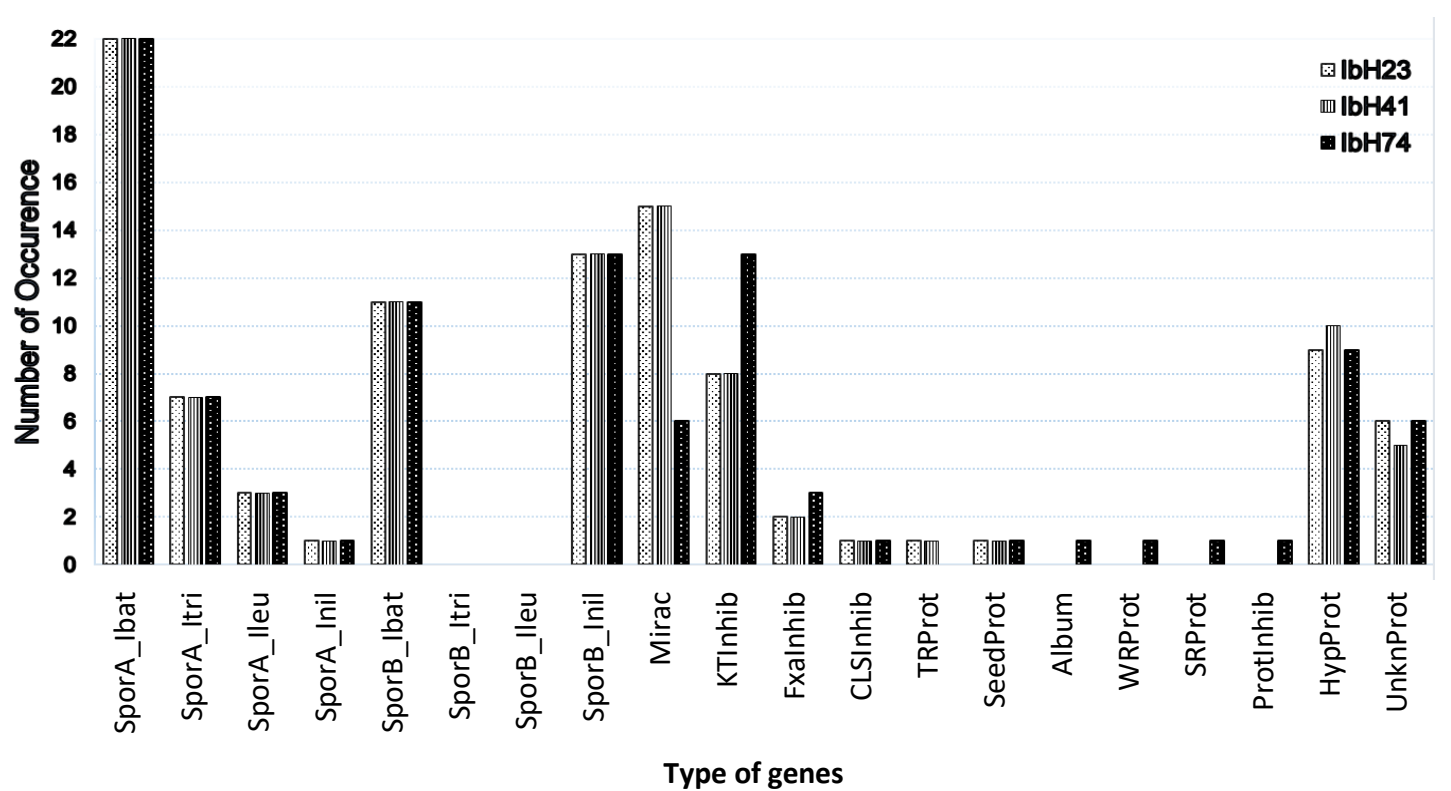

Figure 4. Distribution of genes type and the number of its occurrence in $\mathrm{IbH} 23$, IbH41, and $\mathrm{IbH} 74$ from sweet potato in response to skinning injury based on BLASTX 100 hits

\section{Similarity of sporamins with miraculin, KTIs, and other genes}

Sporamin is exclusively found in storage roots of sweet potato (Hattori et al. 1989). Spors A and B have been isolated from Ipomoea species. A total of 100 hits were retrieved by BLASTX search. Our partial cDNAs showed that spors A and B were greatest (57/100). The highest percentage occurrence of spor A has been isolated from $I$. batatas (SporA_Ibat: 22/100) followed by I. trifida (SporA_Itri: 7/100), I. leucantha (SporA_Ileu: 3/100) and the lowest occurrence in I. nil (SporA_Inil: 1/100) were distributed equally in $\mathrm{IbH} 23,-41$, and -74 . In contrast, spor B was only found in I. batatas (SporB_Ibat: 11/100) and I. nil (SporB_Inil: 13/100).

Besides spors A and B, the second most abundant gene that showed similarity to $\mathrm{IbH} 23,-41$, and -74 was miraculin (mirac). The highest occurrence was found in $\mathrm{IbH} 23$ and $\mathrm{IbH} 41$ with the equal amount of Mirac (15/100) and less than that of $\mathrm{IbH} 23$ and $\mathrm{IbH} 41$ in $\mathrm{IbH} 74(6 / 100$ occurrence) (Figure 4). Mirac has been studied in eggplants infested with Colorado potato beetle (López-Galiano et al. 2017) and citrus plants under insect infestation and salinity stress (Podda et al. 2014).

The third most abundance gene that showed similarity to $\mathrm{IbH} 23,-41$, and -74 was Kunitz trypsin inhibitors (KTInhib) with the occurrence being similar in $\mathrm{IbH} 23$ and IbH41 (7/100) and a slightly higher in IbH74 (8/100). Another was Factor Xa Inhibitor (FXaInhib), with an occurrence a slightly higher in IBH74 (3/100) while in $\mathrm{IbH} 23$ and $\mathrm{IbH} 41$ the occurrence was less (2/100). Another type of inhibitor was a proteinase inhibitor (ProtInhib) exclusively found only in IbH74 (Figure 4). In this study $\mathrm{IbH} 23,-41$, and -74 showed similarities with three inhibitors such as KTInhib (Guerra et al. 2015; Chan et al. 2017), FXaInhib (Salu et al. 2014), subtilisin inhibitor
(CLSInhib) (Bunyatang et al. 2016; Yu et al. 2017), and proteinase inhibitor (Chen et al. 2014; Kidrič et al. 2014; Fischer et al. 2015; Shamsi et al. 2016). IbH23, -41, and 74 showed $29-36 \%$ identity with KTInhib which are commonly found in seeds of Leguminosae family. These inhibitors are toxic to insects, pests, and pathogens (Cruz et al. 2013), and function in regulating endogenous proteolytic activities in storage organs as well as a defense against mechanical wounding and insects, pathogens and herbivory attacks (Macedo et al. 2016). Only IbH74 showed similarities with these three inhibitors, while $\mathrm{IbH} 23$ and IbH41 only showed similarities with two inhibitors (Figure 4).

The three partial cDNA has equal amount of CLSI gene (CLSInhib:1/100). This study found that tumor-related protein (TRProt) gene was specific to $\mathrm{IbH} 23$ and $\mathrm{IbH} 41$, while genes such as albumin (Album) (Bhunia et al. 2014), wound-responsive protein (WRProt) (Wong et al. 2013), and sexual organ-responsive protein (SRProt) were exclusively found only in IbH74 (Figure 4). Therefore, these cDNAs especially IbH74 should be studied further to reveal its potential roles in protecting crop plants against insects, pathogens, herbivores, wounding as well as its function as a storage protein.

Sporamin has four signature cysteine residues, for example, Cys85, Cys135, Cys198, and Cys209. Multiple sequence alignment shows that the $\mathrm{IbH} 23,-41$, and -74 cDNAs are missing the first 126 amino acid residues. The reason is that it requires an effective reverse transcriptase to the extreme $5^{\prime}$ end of the mRNA. Therefore, $\mathrm{IbH} 23,-41$, and -74 only have the last 3 Cys regions (Cys135, Cys198, and Cys209) of sporamin. Although spors A and B have four Cys residues, the significant difference between spors $\mathrm{A}$ and $\mathrm{B}$ from Ipomoea sp. with other genes from other plants was the Cys 85 and Cys 84 positions, respectively 
(Figure 5). Therefore, four conserved Cysteine residues may imply a putative three-dimensional common structure (Yeh et al. 1997). However, the different reactive site at the first Cys residues between spors and those of other genes may result in differences in cysteine disulfide bonding (Yeh et al. 1997). Cys residues have been shown to function in redox regulation and protein stability (Skryhan et al. 2015). Thus, this may represent a uniqueness of spors when compared to miraculins and other KIs genes. Further studies regarding the sporamin reactive site is needed in order to elucidate its function.

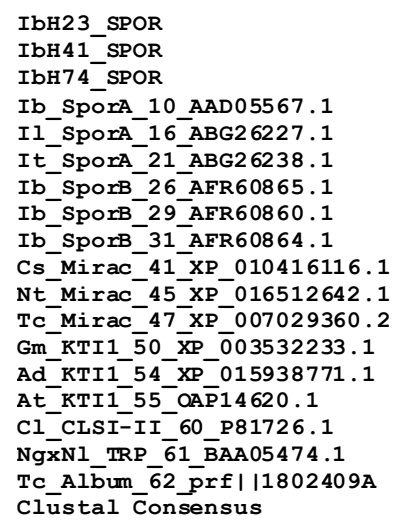

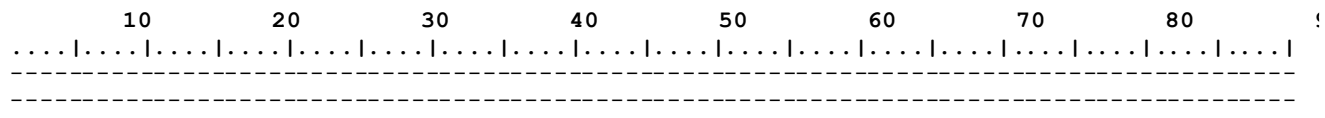

--MEALTLALF LALSLYLLPNPAHSGFNP IRL PTTHE PASSET PVLDINGDEVRAGGNYYLVSA ILGACGGGLRLAHLDLMN -NCASDVI -MKAFT LALFLALSLYLL PN PAHSRFN PIRLPTTHEP PPSETPVLD INGDEVRAGGNYYMVSA IWGAGGGGLRLAHLDMMS -KCAS DVT --MKAFT LALF LALSLY LL PNPAHSRFNP IR LPTTHEP P PSE TPVLD I GGDEVRAGGNYYMVSA IWGAGGGGLRLAH LDMMS -KCASDVT --MKAF--ALFFVLSLY LL PNPT HSKFNP IRLRPAHE TASSET TVLD I NGDEVRAGENYYMVSA IWGA GGGGLRLVRLDSSSNE CASDVI --MKAL--ALFFVLSLYLLANPAYSKFNP IRLRPARETASSETPVLD INGDEVRAGENYYIVSA IWGAGGGGLRLVRLDSSSNE CASDVI -MKAL--ALLFVLSLYLL PNPAHSKFNP IRLRPAHETASSETPVLD I GDEVRAGENYYIVSA IWGAGGGGLRLVRLDSSSNE CAS DVI

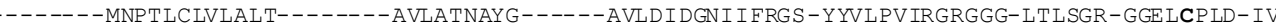
-MKTNQLFLPFLIFTISFN-------SFLS SAAEAP---- - PAVI DIAGKKLRTGVDYYI LPVVRGRGGG-LTLDST - GNE SCPLDAVV --MKT-AVFLALS LLLCA------------NAAP-----DPVLDIS GKKLRTGT DYYI LPVFRGRGGG-LTLAST -GNE SCP LD -VV --MKST S----LFA IF L LCAFT ------S-YL PSATAQ-----DVL DVD GD P I RNG F I YYVL PA IRGN - GGG I ERAAL-GKDTCP IT -VV --MKATT TT TNVFA IF I LFAFI------FNHLPS LATA-----ELVDT D GNL I RNGGLYYI LPVFRGN-GGG IGRTST-GNETCPLT-VV -MTKTTKTMNPKFYLVLALT--------AVLASNAYG------AVVI DGNTMFHES-YYVLPVIRGRGGG-LTLAGR-GGQ PCPYD-IV -

--MKTATAVVLLLFAFT SKSY-------FFGVANAANS-----PVLDT DGDE LQTGVQYYVLSS ISGAGGGGLALGRA - TGQSCPEI -VV

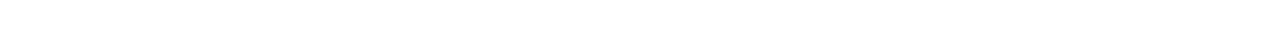

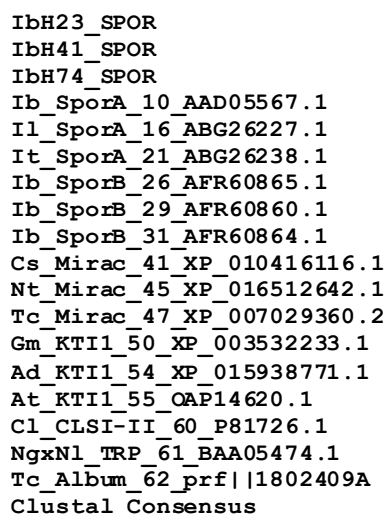

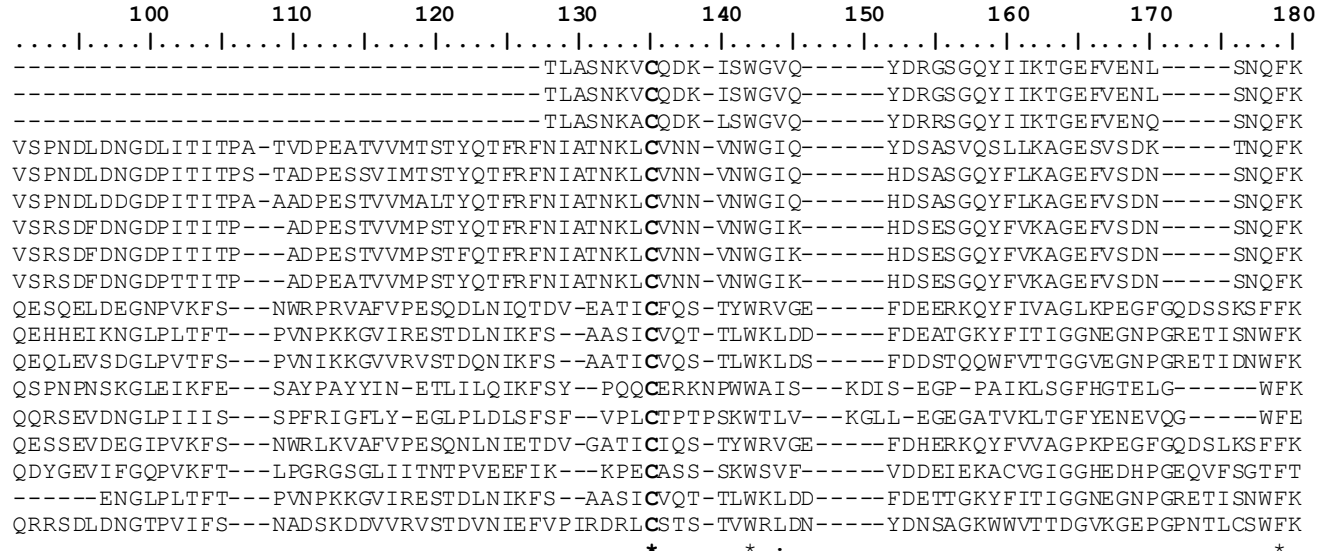

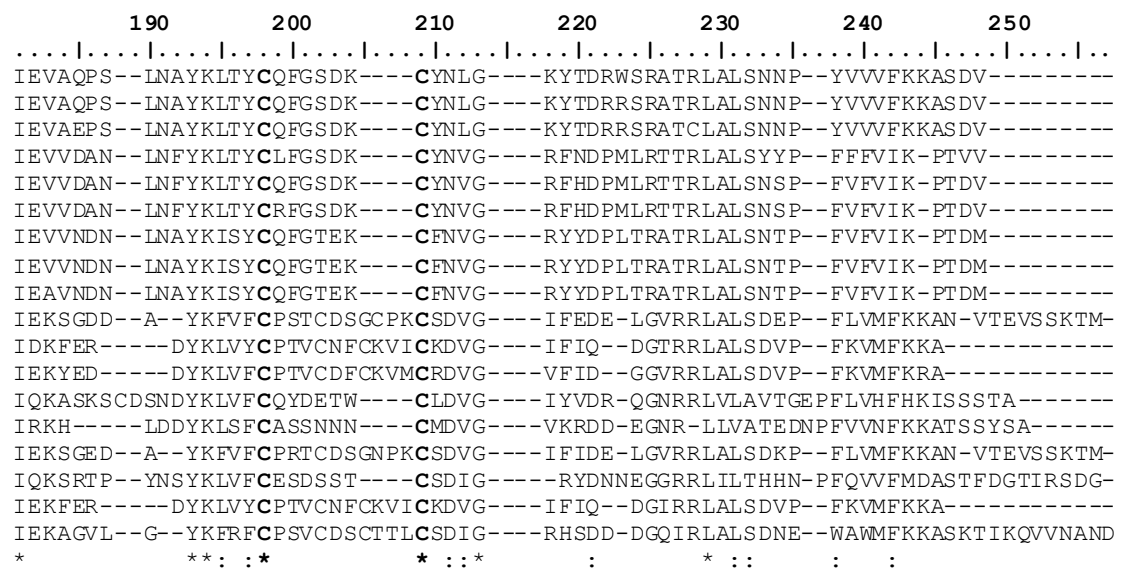

Figure 5. Alignment of the deduced amino acid sequences of partial cDNAs $\mathrm{IbH} 23$, IbH41, and IbH74 encoded sporamin from Ipomoea batatas (Ib); spors A and B from I. batatas (Ib), I. leucantha (Il), I. trifida (It); miraculin (Mirac) from Camelina sativa (Cs), Nicotiana tabacum (Nt), Theobroma cacao (Tc); KTIs from Glycine max (Gm), Arachis duranensis (Ad), Arabidopsis thaliana (At); subtilisin inhibitor from Canavalia lineata $(\mathrm{Cl})$; tumor-related protein (TRP) from Nicotiana glauca x Nicotiana langsdorffii (NgxNl); and albumin (Album) from Theobroma cacao. The corresponding GenBank accession numbers are noted at the end of each line. Cysteine residues are shown as black bold letters on a gray background. 
Phylogenetic relationship among IbSpors cDNAs and Spors from Ipomoea species, miraculin, KTIs and other genes from various plant species

In the present study, $\mathrm{IbH} 23$ and $\mathrm{IbH} 41$, as well as IbH74, were used to study their phylogenetic relationship with sporamins from ESTs available in databases. An unrooted phylogenetic tree was created in order to determine the relationship between the sporamins from Ipomoea sp., and other related genes from other plant species. As shown in Figure 6, the spors proteins from various Ipomoea sp. could be divided into three distinct classes (I to III). Class I contained spor A, Class II contained spor B and Class III contained IbH23, -41, and 74. Other genes except spors were categorized in different classes. The tree shown in Figure 6 indicated that a distinction can be made between spors $\mathrm{A}$ and $\mathrm{B}$ from Ipomoea sp. compared with $\mathrm{IbH} 23,-41$, and -74 which appears to be less related. These results were supported by the BLASTX search in which the sequences shared identity of $42-62 \%$ (IbH23 and $\mathrm{IbH} 41$ ) and $40-61 \%$ ( $\mathrm{IbH} 74)$ to spors A and B previously identified in other sweet potato species. Based on these low to medium shared identity with spors A and B in other Ipomoea sp., these IbH23, -41, and 74 could be placed in a novel spor B subfamily.

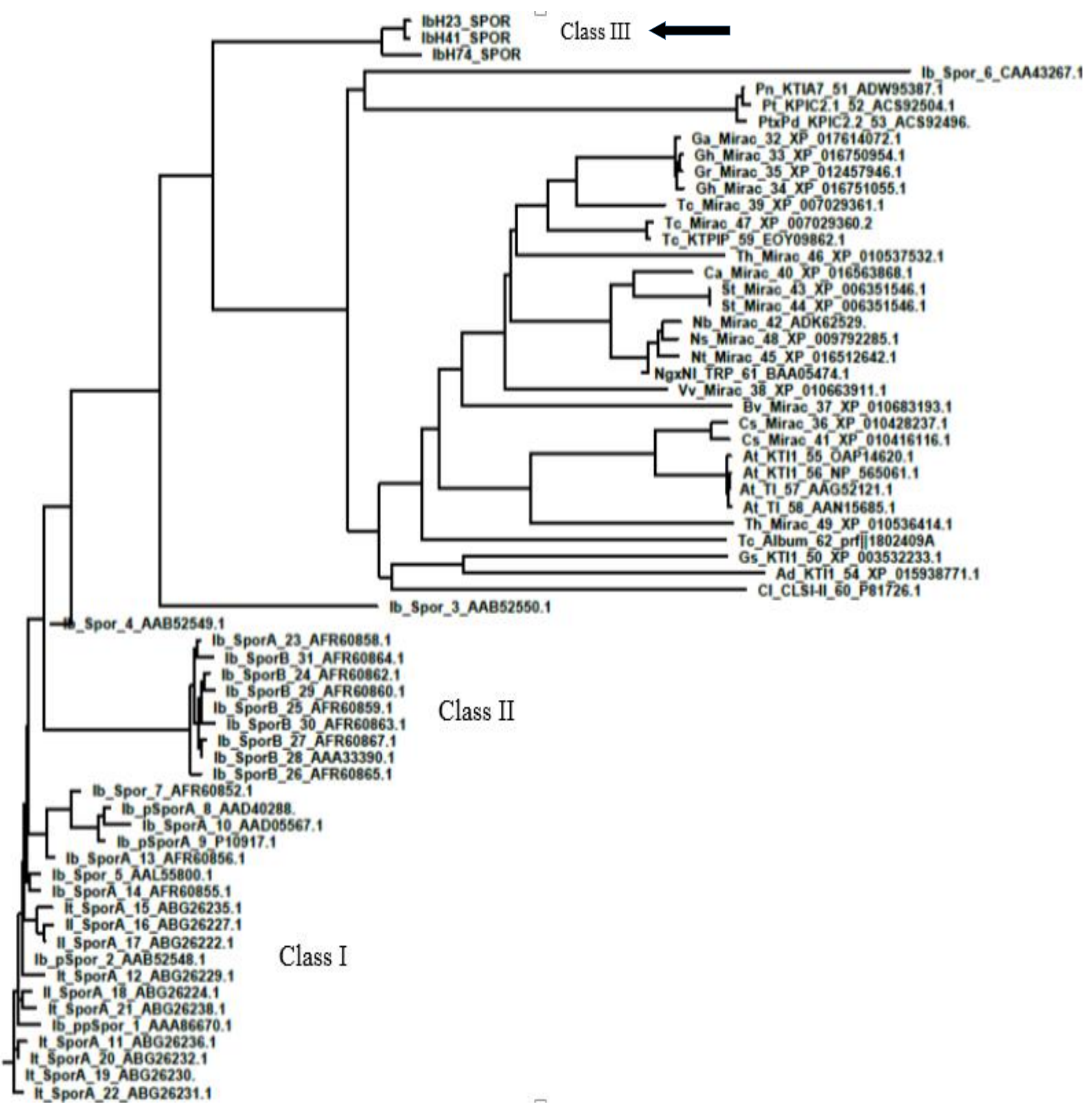

Figure 6. Phylogenetic relationship among IbSpors (IbH23, IbH41, and IbH74) (Class III with an $\square$ ) and Spors from Ipomoea sp. and other genes from other plant species. The amino acid sequences were aligned by the ClustalX2 program, and the neighbor-joining tree was drawn using FigTree v1.4.3. The corresponding GenBank accession numbers are noted in the phylogenetic tree 
From phylogenetic analysis, multiple alignment and domain analysis of $\mathrm{IbH} 23,-41$, and -74 in sweet potato in response to skinning injury, we concluded that spor A family members may be conserved among I. batatas, $I$. leucantha, I trifida and I. nil, while spor B were equally conserved in I. batatas and I. nil. The difference in Cys residues at Cys 85 position may affect protein disulfide bonding that could lead to different classes in phylogenetic relationship between spors A and B with other genes. Our results suggested that $\mathrm{IbH} 23,-41$, and -74 are presumably new members of spor genes subfamily $B$. The phylogenetic analysis together with the Cys domain motif analysis presented here will facilitate the functional annotation and study of sweet potato sporamins.

In conclusion, DNA sequence comparisons show that these three cDNAs share 92-99\% identity among themselves and 40-62\% identity with spors A and B. ACPPCR products showed skinned up-regulated ( $\mathrm{IbH} 23$ and $\mathrm{IbH74)}$ and transient regulated ( $\mathrm{IbH} 41)$ expressions. Amino acid and phylogenetic analysis suggest that these partial cDNA clones can be classified into a new sporamin gene subfamily B. The ORF contained three conserved cysteine residues that usually found in spors $\mathrm{A}$ and $\mathrm{B}$, except for the first cysteine due to missing ORF, the first amino acid at 5'. The $3^{\prime}$-UTR sequence of these genes may have an impact on understanding the role of sporamin, not only function as a major storage protein in sweet potato but may be applied in other tuberous roots that spoiled easily due to postharvest physiological deterioration such as in cassava.

\section{ACKNOWLEDGEMENTS}

Funding for this work was provided by Borlaug Fellowship 2011 from the United State Department of Agriculture - Foreign Agricultural Service to JE.

\section{REFERENCES}

Altschul SF, Wootton JC, Gertz EM, Agarwala R, Morgulis A, Schäffer A, Yu YK. 2005. Protein database searches using compositionally adjusted substitution matrices. FEBS J 272 (20): 5101-5109.

Bhunia RK, Chakraborty A, Kaur R, Gayatri T, Bhattacharyya J, Basu A, Maiti MK, Sen SK. 2014. Seed-specific increased expression of 2 S albumin promoter of sesame qualifies it as a useful genetic tool for fatty acid metabolic engineering and related transgenic intervention in sesame and other oilseed crops. Plant Mol Biol 86: 351-365.

Booth RH, Burton WG. 1983. Future needs in potato post-harvest technology in developing countries. Agric Ecosys Environ 9 (3): 269 280

Bunyatang O, Chirapongsatonkul N, Bangrak P, Henry R, Churngchow N. 2016. Molecular cloning and characterization of a novel bi-functiona $\alpha$-amylase/subtilisin inhibitor from Hevea brasiliensis. Plant Physiol Biochem 101: 76-87.

Chan SN, Bakar NA, Mahmood M, Ho C-L, Dzaki NM, Shaharuddin NA. 2017. Identification and expression profiling of a novel Kunitz trypsin inhibitor (KTI) gene from turmeric, Curcuma longa, by real-time quantitative PCR (RT-qPCR). Acta Physiol Plant 39: 12. DOI:10.1007/s11738-016-2311-7.

Chen PJ, Senthilkumar R, Jane WN, He Y, Tian Z, Yeh KW. 2014. Transplastomic Nicotiana benthamiana plants expressing multiple defense genes encoding protease inhibitors and chitinase display broad-spectrum resistance against insects, pathogens and abiotic stresses. Plant Biotechnol J 12 (4): 503-515.

Cruz AC, Massena FS, Migliolo L, Macedo LL, Monteiro NK, Oliveira AS, Macedo FP, Uchoa AF, de Sá MFG, Vasconcelos IM. 2013. Bioinsecticidal activity of a novel Kunitz trypsin inhibitor from Catanduva (Piptadenia moniliformis) seeds. Plant Physiol Biochem 70: 61-68.

Dean C, Tamaki S, Dunsmuir P, Favreau M, Katayama C, Dooner H, Bedbrook J. 1986. mRNA transcripts of several plant genes are polyadenylated at multiple sites in vivo. Nucleic Acids Res 14 (5): 2229-2240.

Ding LC, Hu CY, Yeh KW, Wang PJ. 1998. Development of insectresistant transgenic cauliflower plants expressing the trypsin inhibitor gene isolated from local sweet potato. Plant Cell Rep 17 (11): 854860 .

Dutt M, Dhekney SA, Soriano L, Kandel R, Grosser JW. 2014. Temporal and spatial control of gene expression in horticultural crops. Hort Res 1: 14047. DOI:10.1038/hortres.2014.47.

Effendy J, Efendi D, Khumaida N, Wattimena GA. 2017. Functional classification of skinning injury responsive genes in storage roots of sweet potato. J Agron Indones 45 (1): 36-42.

Effendy J, LaBonte DR, Baisakh N. 2013. Identification and expression of skinning injury-responsive genes in sweet potato. J Am Soc Hort Sci 138: $210-216$.

Fischer M, Kuckenberg M, Kastilan R, Muth J, Gebhardt C. 2015. Novel in vitro inhibitory functions of potato tuber proteinaceous inhibitors. Mol Genet Genomics 290 (1): 387-398.

Flores T, Alape-Girón A, Flores-Díaz M, Flores HE. 2002. Ocatin. A novel tuber storage protein from the Andean tuber crop oca with antibacterial and antifungal activities. Plant Physiol 128 (4): 12911302.

Food and Agriculture Organization of the United Nations. 2016. FAOSTAT Database. Rome, Italy. FAO. http://www.fao.org/faostat/en/\#data/QC.

Fujiwara T, Nambara E, Yamagishi K, Goto DB, Naito S. 2002. Storage proteins. The Arabidopsis Book/Amer Soc Plant Biol. 1.

Guerra FP, Reyes L, Vergara-Jaque A, Campos-Hernández C, Gutiérrez A, Pérez-Díaz J, Pérez-Díaz R, Blaudez D, Ruíz-Lara S. 2015. Populus deltoides Kunitz trypsin inhibitor 3 confers metal tolerance and binds copper, revealing a new defensive role against heavy metal stress. Environ Exp Bot 115: 28-37.

Hattori T, Fukumoto H, Nakagawa S, Nakamura K. 1991. Sucroseinduced expression of genes coding for the tuberous root storage protein, sporamin, of sweet potato in leaves and petioles. Plant Cell Physiol 32 (1): 79-86.

Hattori T, Nakagawa S, Nakamura K. 1990. High-level expression of tuberous root storage protein genes of sweet potato in stems of plantlets grown in vitro on sucrose medium. Plant Mol Biol 14: 595604.

Hattori T, Nakagawa T, Maeshima M, Nakamura K, Asahi T. 1985. Molecular cloning and nucleotide sequence of cDNA for sporamin, the major soluble protein of sweet potato tuberous roots. Plant Mol Biol 5: 313-320.

Hattori T, Yoshida N, Nakamura K. 1989. Structural relationship among the members of a multigene family coding for the sweet potato tuberous root storage protein. Plant Mol Biol 13 (5): 563-572.

Kidrič M, Kos J, Sabotič J. 2014. Proteases and their endogenous inhibitors in the plant response to abiotic stress. Bot Serb 38: 139158.

López-Galiano MJ, Ruiz-Arroyo VM, Fernández-Crespo E, Rausell C, Real MD, García-Agustín P, González-Bosch C, García-Robles I. 2017. Oxylipin mediated stress response of a miraculin-like protease inhibitor in Hexanoic acid primed eggplant plants infested by Colorado potato beetle. J Plant Physiol 215: 59-64.

Macedo MLR, Ribeiro SF, Taveira GB, Gomes VM, de Barros KM, Maria-Neto S. 2016. Antimicrobial activity of ILTI, a Kunitz-type Trypsin Inhibitor from Inga laurina (SW.) Willd. Curr Microbiol 72 (5): 538-544.

Maeshima M, Sasaki T, Asahi T. 1985. Characterization of major proteins in sweet potato tuberous roots. Phytochemistry 24 (9): 1899-1902.

Murakami S, Hattori T, Nakamura K. 1986. Structural differences in fulllength cDNAs for two classes of sporamin, the major soluble protein of sweet potato tuberous roots. Plant Mol Biol 7 (5): 343-355. 
Podda A, Simili M, Del Carratore R, Mouhaya W, Morillon R, Maserti BE. 2014. Expression profiling of two stress-inducible genes encoding for miraculin-like proteins in citrus plants under insect infestation or salinity stress. J Plant Physiol 171 (1): 45-54.

Ponniah SK, Thimmapuram J, Bhide K, Kalavacharla VK, Manoharan M. 2017. Comparative analysis of the root transcriptomes of cultivated sweet potato (Ipomoea batatas [L.] Lam) and its wild ancestor (Ipomoea trifida [Kunth] G. Don). BMC Plant Biol 17 (1): 9. DOI: 10.1186/s12870-016-0950-X.

Qiu L, Wu T, Dong H, Wu L, Cao J, Huang L. 2013. High-level expression of sporamin in transgenic Chinese cabbage enhances resistance against diamondback moth. Plant Mol Biol Rep 31 (3) 657-664.

Rajendran S, Lin IW, Chen MJ, Chen CY, Yeh KW. 2014. Differential activation of sporamin expression in response to abiotic mechanical wounding and biotic herbivore attack in the sweet potato. BMC Plant Biol 14 (1): 112.

Rees D, Van Oirschot QEA, Amour R, Rwiza E, Kapinga R, Carey, T. 2003. Cultivar variation in keeping quality of sweet potatoes Postharvest Biol Tech 28 (2): 313-325.

Salu BR, Ferreira RS, Brito MV, Ottaiano TF, Cruz JWM, Silva MCC, Correia MTS, Paiva PM, Maffei FHA, Oliva MLV. 2014. CrataBL, a lectin and Factor Xa inhibitor, plays a role in blood coagulation and impairs thrombus formation. Biol Chem 395 (9): 1027-1035.

Scherf KA, Koehler P, Wieser H. 2016. Gluten and wheat sensitivities-an overview. J Cereal Sci 67: 2-11.

Senthilkumar R, Yeh KW. 2012. Multiple biological functions of sporamin related to stress tolerance in sweet potato (Ipomoea batatas Lam). Biotechnol Adv 30 (6): 1309-1317.
Shamsi TN, Parveen R, Amir M, Baig MA, Qureshi MI, Ali S, Fatima S. 2016. Allium sativum protease inhibitor: a novel kunitz trypsin inhibitor from garlic is a new comrade of the serpin family. PloS One 11 (11): e0165572. DOI:10.1371/journal.pone.0165572.

Shewry PR. 2003. Tuber storage proteins. Ann Bot 91: 755-69.

Skryhan K, Cuesta-Seijo JA, Nielsen MM, Marri L, Mellor SB, Glaring MA, Jensen PE, Palcic MM, Blennow A. 2015. The role of cysteine residues in redox regulation and protein stability of Arabidopsis thaliana starch synthase 1 . PloS One 10 (9): e0136997. DOI: 10.1371/journal.pone.0136997.

Wang SJ, Lan YC, Chen SF, Chen YM. Yeh KW. 2002. Wound response regulation of the sweet potato sporamin gene promoter region. Plant Mol Biol 48: 223-231.

Wong MT, Siah CH, Faridah QZ, Mohamed R. 2013. Characterization of wound responsive genes in Aquilaria malaccensis. J Plant Biochem Biotechnol 22 (2): 168-175.

Xue YL, Miyakawa T, Nakamura A, Hatano K, Sawano Y, Tanokura M. 2015. Yam tuber storage protein reduces plant oxidants using the coupled reactions as carbonic anhydrase and dehydroascorbate reductase. Mol Plant 8 (7): 1115-1118.

Yeh KW, Chen JC, Lin MI, Chen YM, Lin CY. 1997. Functional activity of sporamin from sweet potato (Ipomoea batatas Lam.): a tuber storage protein with trypsin inhibitory activity. Plant Mol Biol 33: 565-570.

Yu J, Li Y, Xiang M, Zhu J, Huang X, Wang WJ, Tan R, Zhou J, Liao H. 2017. Molecular cloning and characterization of $\alpha$-amylase/subtilisin inhibitor from rhizome of Ligusticum chuanxiong. Biotechnol Lett 39 (1): 141-148. 